\title{
Local traditional foods contribute to diversity and species richness of rural women's diet in Ecuador
}

\author{
Dolores Penafiel ${ }^{1, *} \odot$, Holger Cevallos-Valdiviezo ${ }^{2}$, Ramón Espinel ${ }^{1}$ and \\ Patrick Van Damme 3,4 \\ ${ }^{1}$ Faculty of Life Sciences, Escuela Superior Politécnica del Litoral, Campus Gustavo Galindo, Km 30.5 Vía Perimetral, \\ PO Box 09-01-5863, Guayaquil, Ecuador: ${ }^{2}$ Faculty of Natural Sciences and Mathematics, Escuela Superior \\ Politécnica del Litoral, Guayaquil, Ecuador: ${ }^{3}$ Faculty of Bioscience Engineering, Ghent University, Ghent, Belgium: \\ ${ }^{4}$ Faculty of Tropical AgriSciences, Czech University of Life Sciences, Czech Republic
}

Submitted 6 September 2018: Final revision received 15 May 2019: Accepted 22 May 2019; First published online 28 August 2019

\begin{abstract}
Objective: To evaluate the dietary diversity and the nutrient contribution of traditional foods (locally cultivated and wild) by conducting a food intake study in rural Ecuador.

Design: Repeated $24 \mathrm{~h}$ recalls over a $14 \mathrm{~d}$ interval and frequency of consumption served to simulate the usual diet by the Multiple Source Method. Data on missing visits ( $n 11)$ were imputed using multivariate imputation by chained equations. The intakes of three macro- and six micronutrients were reported. Nutrient Adequacy Ratios, Mean Adequacy Ratio (MAR), Dietary Species Richness (DSR) and Minimum Dietary Diversity for Women were used as measures of dietary quality. A linear quantile mixed model was used to investigate the association between DSR, local species, MAR, age, education and occupation.

Setting: Guasaganda, Cotopaxi (Ecuador).

Participants: Rural, indigenous adult women, non-pregnant and not breastfeeding.

Results: The studied diet had MAR of 0.78 . Consumption of traditional foods contributed $38.6 \%$ of total energy intake. Daily requirements for protein, carbohydrates, Fe and vitamin $\mathrm{C}$ were reached. An extra level of consumption of local species was associated with an increase in median MAR for macronutrients of 0.033 $(P<0.001)$. On the other hand, an extra level of consumption of local species was associated with an increase in median MAR for micronutrients of $0.052(P<0.001)$. Conclusions: We found statistical evidence that traditional foods contribute to adequate intakes of macro- and micronutrients and dietary diversification in the studied population. Future public health interventions should promote the cultivation and consumption of traditional foods to increase the quality of the local diet.
\end{abstract}

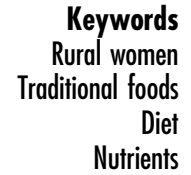

Traditional foods (TF) are edible species that belong to a traditional food system, whether in developed ${ }^{(1)}$ or developing countries ${ }^{(2)}$. In developing countries, the term TF is often associated with traditional food systems of indigenous people which include foods from local and natural environments that are culturally acceptable ${ }^{(2)}$. Importantly, localization is used to emphasize the boundaries and differentiation of a culturally homogeneous community ${ }^{(3)}$. Research on TF is emerging because of social, conservation and economic challenges ${ }^{(1)}$.

Malnutrition in developing countries is a long-lasting burden, despite their diverse agricultural production and availability of wild foods ${ }^{(4)}$. Availability of a diversity of foods seems to be a necessary, but not a sufficient, condition to reach nutrient security ${ }^{(5)}$. Although there is not much evidence to affirm that $\mathrm{TF}$ consumption supplies enough dietary energy, it covers a high share of the micronutrient requirement, and therefore TF are seen as important elements of the food system to fight hidden hunger ${ }^{(6,7)}$. It is currently understood that consumers who have access to selfcultivated foods and foods from wild sources have a dietary diversity which is rich in species ${ }^{(8)}$. Recent research indicates that species richness in the diet of rural women is an adequate indicator for nutrient adequacy in developing countries ${ }^{(9)}$. 
More specifically, studies have shown that eating a variety of local fish species in poor rural communities of Bangladesh provides consumers with $31-40 \%$ of the recommended intake of vitamin A and $\mathrm{Ca}$, respectively ${ }^{(10)}$. In rural villages in Vietnam, eating wild vegetables contributes $21 \%$ of folate intake ${ }^{(11)}$. The consumption of a high variety of local Arctic foods by local Canadians provides them with 87,23 and $37 \%$ of their total daily intake of cholecalciferol, vitamin A and tocopherol, respectively ${ }^{(12)}$. High agricultural biodiversity, cultivated and wild food species, is correlated with high nutrient adequacy ratios for $\mathrm{Zn}$, vitamins $\mathrm{B}_{12}, \mathrm{~B}_{6}$ and $\mathrm{C}$, folate and riboflavin in two rural Kenyan villages ${ }^{(13)}$.

Undoubtedly, the study of TF includes the intake of both locally cultivated and wild foods. In rural areas, diets are often diversified by plant and animal foods obtained from agricultural production ${ }^{(13-17)}$, wild foods from the forest ${ }^{(13,17-21)}$, and wild freshwater fish or fish from aquaculture ${ }^{(10,22-24)}$. However, cultivated and wild TF can coexist in farms (i.e. wild vegetables found around cultivated areas or home gardens); whereas forests are mainly the source of wild TF (i.e. wild fruits and bush meat).

Despite the increasing body of evidence about the nutrient contribution of certain species, the role of a variety of TF in nutrition is still not solid. Nutrition interventions in developing countries require that the nutrient contribution of TF, wild or cultivated, is documented prior to the design of local strategies such as promoting TF consumption or policy development. Ecuador is one of the seventeen megadiverse countries in the world in which research is required to document the nutrient contribution of a diet composed of a variety of TF.

\section{Methods}

The present research documented all edible items present in the rainy season using a food intake study. For TF, the analysis included only foods that were: (i) locally cultivated or found in the wild at Guasaganda (geographical location); (ii) recorded during the food intake study (dietary surveys); (iii) collected in situ (species identification); and (iv) cooked locally (recipe preparation).

\section{Study area and participants}

Guasaganda is a tropical rural parish located in central Ecuador in the Andes region with altitudes that vary between 250 and $1000 \mathrm{~m}$ above sea level. This geographical area was selected because it is a centre of food biodiversity ${ }^{(25)}$. The population (about 3900 inhabitants) is mainly indigenous ${ }^{(26)}$. Rural adult women of indigenous ethnicity were selected to be the study participants because they are vulnerable to overweight and micronutrient deficiencies and are the poorest segment of the population ${ }^{(27)}$. The data collection was conducted during the rainy season assuming that is the highest peak of food biodiversity ${ }^{(13)}$.

\section{Dietary surveys}

Recording the consumption of foods is a methodology widely used to assess the nutrient intake and dietary diversity of populations ${ }^{(28)}$. One of the most commonly used approaches is the $24 \mathrm{~h}$ recall since it is very practical, has a relatively low cost and can be administered by trained interviewers $^{(28,29)}$. The present survey was conducted between March and May 2011 and started with a $24 \mathrm{~h}$ recall questionnaire which was repeated after $14 \mathrm{~d}$ in a second visit. Two non-consecutive visits can help to reduce intra-personal variability and to further compute usual food intakes ${ }^{(30)}$. The studied individuals were adult rural women (older than 18 years) living in Guasaganda who were neither pregnant nor breast-feeding and were residents of Guasaganda for more than a year. Women were interviewed because they are responsible for food preparation in rural areas.

The questionnaire recalled all food eaten in the previous $24 \mathrm{~h}$, including the amount of food consumed (using standardized measuring tools), the local name of each food used to prepare a recipe with its food source (i.e. collected/ hunted or cultivated, purchased but not processed, purchased or processed food, food aid), brands of commercialized foods and cooking method (i.e. raw, cooked, fried, oven). Also, demographic information documented age, occupation and education level (more details on the levels used for occupation and education can be found in Table 1). Interviews were administered to participants at their house and in Spanish, by trained interviewers supervised by the main author (D.P.) who speaks the local language. Interviews conducted by the author served as control performance for the other interviewers. Protocols were developed using literature on dietary surveys ${ }^{(31,32)}$ and food biodiversity manuals ${ }^{(33)}$.

The number of women to be interviewed was calculated by using G*Power software (general power analysis) version 2009, aiming for a precision of $0.5 \mathrm{SD}$ and $80 \%$ power based on the mean Traditional Food Diversity Score (TFDS; 9.5 (SD 3.5)) from a study in Peruvian indigenous people ${ }^{(34)}$, generating 128 individuals. We multiplied the latter number by 1.2 assuming the villages as clusters. In addition, twenty-four households (15\%) were added for contingency considering that in rural areas some households may drop out of the study. The final calculated sample size was 178 .

Sampling was done following the recommendation from the Food and Nutrition Technical Assistance Project manuals ${ }^{(35,36)}$ to use a two-step cluster design. In the first step, villages were selected from a list of all villages in the parish of Guasaganda retrieved from the Ecuadorian Institute of National Surveys using the probability proportional to size method. The second step involved a random selection of households within each village using a map 
Table 1 Demographic characteristics of the studied rural women ( $n$ 178) and their respective partners from Guasaganda, Ecuador

\begin{tabular}{lrr}
\hline Characteristic & $n$ & $\%$ \\
\hline Occupation & & \\
Agricultural employment & 48 & $27 \cdot 0$ \\
Non-agricultural employment & 19 & $5 \cdot 1$ \\
Housewife & 33 & $18 \cdot 5$ \\
Student & 3 & $1 \cdot 7$ \\
Family agriculture & 80 & $44 \cdot 9$ \\
None & 5 & $2 \cdot 8$ \\
Main home income & & \\
Agricultural employment & 88 & $41 \cdot 1$ \\
Non-agricultural employment & 60 & $28 \cdot 0$ \\
Family agriculture & 25 & $11 \cdot 7$ \\
None & 5 & $2 \cdot 3$ \\
Education & & \\
Primary school & 108 & $60 \cdot 7$ \\
Secondary school & 46 & $25 \cdot 8$ \\
University & 5 & $2 \cdot 8$ \\
Technical training & 1 & $0 \cdot 6$ \\
Other & 17 & $9 \cdot 6$ \\
None & 1 & $0 \cdot 6$ \\
Marital status & & \\
With partner & 156 & $87 \cdot 6$ \\
Without partner & 22 & $12 \cdot 4$ \\
\hline
\end{tabular}

created by us that positioned each house using GPS (Global Positioning Satellite) points. By this method, ten villages were selected to be studied out of the thirty-eight. In each household, one woman in charge of TF preparation was interviewed. In each visit, a kit containing a standardized cup, dish and spoon were provided by the interviewer to the participant, aiming for more accuracy when describing portion sizes.

A third visit to the villages (June 2012) was done to record the frequency of consumption of twenty local foods using an FFQ querying frequencies of consumption in times per day, week and month. The consumption frequency is essential to calculate usual intakes with the Multiple Source Method (MSM) using MSM software version 1.0.1 (https://msm. dife.de/).

\section{Traditional food identification}

Only edible species found in the area were identified as TF. A local guide assisted us to find the wild plant species with edible use in the forest of Sacha Wiwua (Central Guasaganda) and crops in surrounding farms. We collected all plants with edible use in 2012 (from June until August) following the methodology described in the literature ${ }^{(37,38)}$. The Ecuadorian Ministry of Environment provided a scientific permit allowing the collection of edible plant samples (03-12IC-FAU-FLO-OPAC/MA). Animal samples were not collected because this was not allowed by the Ministry of Environment, aiming to preserve local animal species. Scientific names of plants were given following the botanical binomial nomenclature. For the latter, we used the official names as registered in a web catalogue (www. theplantlist.org, version 1.1). The scientific names for local birds, mammals and fish were retrieved from three web catalogues of Ecuador ${ }^{(39-41)}$.

\section{Recipe preparation}

The present study recorded traditional recipes to document the amount of each ingredient per total weight for the final dish (e.g. chicken soup with plantain). We prepared traditional recipes at least three times to correct for different cooking recipes. Preparation of the latter was done using local ingredients, in local kitchens and using local utensils. Each ingredient was weighed using a digital scale $( \pm 0.01 \mathrm{~g})$ which measured the ingredients in grams to two decimal places (Mettler Toledo, EL 2001). The mixed method for recipe calculation recommended by the FAO was used to correct nutrients from a food composition table (FCT) at ingredient level by using nutrient retention factors $^{(42)}$ and yield factors ${ }^{(43)}$ according to the preparation method reported in the $24 \mathrm{~h}$ recall. By this method, the percentage of weight change, or the percentage of nutrient retention or loss, due to cooking was corrected for. For example, when plantain is cooked in a soup it tends to absorb water and increase its weight but also loses vitamin $\mathrm{C}$ due to heating. By this method, we could calculate the final weight and vitamin $\mathrm{C}$ content by correcting the values obtained from the FCT for plantain in the raw state.

\section{Analysis}

For the statistical analysis, data from the first visit included 178 sampled women and for the second visit 167 . To simulate the usual diet the third visit included only 127 women.

Descriptive statistics were performed in $\mathrm{R}$ software (2011) to get insight into the demographic characteristics (see Table 1) and the usual diet of the studied group. All food intake data from the $24 \mathrm{~h}$ recalls were managed in Lucille application version 0.1.6.8. The latter exported an Excel document with the list of all consumed foods, the quantified intake in grams per person and nine nutrient intakes per person per day. This Excel data set (available at doi:10.6084/m9.figshare.7851584) was used for further analysis in $\mathrm{R}$, after handling missing data and outliers.

Lucille merged the intake in grams with the nutrient content of foods from a compiled FCT following a standard methodology ${ }^{(44)}$. We used the FCT of Peru ${ }^{(45)}$ and Central America $^{(46)}$ assuming that these are similar geographical areas which supply foods with comparable nutritional content (each nutrient per $100 \mathrm{~g}$ ). The FCT of Ecuador was used only for foods that were not found in the other two FCT because it is a very old publication ${ }^{(47)}$. The US Department of Agriculture's National Nutrient Database for Standard Reference was the resource for missing nutrients ${ }^{(48)}$. The studied nutrients included protein, fat, carbohydrates, fibre, $\mathrm{Ca}, \mathrm{Fe}, \mathrm{Zn}$, vitamin A and vitamin C. Vitamin D was not studied since in Ecuador this vitamin is mainly synthesized in the skin under high sun exposure ${ }^{(49)}$. Iodine was also not considered because $99 \%$ of the Ecuadorian population consumes iodized salt ${ }^{(50)}$. We calculated total energy intake in kilojoules using Atwater factors for macronutrients because under-reporting of 
Table 2 Descriptive statistics of women's diet in Guasaganda, Ecuador, during the rainy season of 2011 ( $n$ 178), the percentage of women below the Estimated Average Requirement (EAR) for the listed nutrients and the Nutrient Adequacy Ratio (NAR)

\begin{tabular}{|c|c|c|c|c|c|c|c|}
\hline Nutrient (unit) & Q1 & Median & Q3 & EAR & $\%<$ EAR & NAR & $P$ value* \\
\hline Protein $(\mathrm{g})$ & $34 \cdot 1$ & $46 \cdot 1$ & $57 \cdot 9$ & $36 \cdot 3$ & 28 & 1.32 & $<0.001$ \\
\hline Total fat $(\mathrm{g})$ & $26 \cdot 2$ & $35 \cdot 1$ & $42 \cdot 4$ & $29 \cdot 7$ & 37 & 1.21 & $<0.001$ \\
\hline Total carbohydrates (g) & $167 \cdot 4$ & $200 \cdot 1$ & 253.5 & 167 & 24 & 1.25 & $<0.001$ \\
\hline Available carbohydrates $(\mathrm{g})$ & $162 \cdot 1$ & 191.8 & 241.4 & - & - & - & - \\
\hline Dietary fibre $(\mathrm{g})$ & $5 \cdot 3$ & 7.7 & 10.9 & 25 & 98 & 0.35 & - \\
\hline $\mathrm{Ca}(\mathrm{mg})$ & 237.7 & $370 \cdot 6$ & $508 \cdot 8$ & 750 & 95 & 0.53 & - \\
\hline $\mathrm{Fe}(\mathrm{mg})$ & $6 \cdot 1$ & $7 \cdot 7$ & $10 \cdot 8$ & $6 \cdot 87$ & - & 1.57 & $<0.001$ \\
\hline $\mathrm{Zn}(\mathrm{mg})$ & $4 \cdot 3$ & $5 \cdot 6$ & $7 \cdot 2$ & $5 \cdot 8$ & 35 & 1.01 & 0.776 \\
\hline Vitamin A (RE) & 253.8 & $350 \cdot 1$ & 485.6 & 464 & 72 & 0.94 & - \\
\hline $\begin{array}{l}\text { Vitamin C (mg) } \\
\text { MAR }\end{array}$ & $51 \cdot 5$ & 74.5 & $110 \cdot 1$ & $\begin{array}{l}75 \cdot 6 \\
0.78\end{array}$ & 51 & $1 \cdot 31$ & 0.026 \\
\hline
\end{tabular}

Q1, first quartile; Q3, third quartile; RE, retinol equivalents; MAR, Mean Adequacy Ratio.

The EAR for available carbohydrates was not used.

The EAR cut-off method was not used for $\mathrm{Fe}$ as it does not meet the conditions for this methodology ${ }^{(30)}$.

Q1, median and Q3 cannot be summed up to obtain the composition per $100 \mathrm{~g}$, nor for estimation of energy intake using Atwater factors.

*Wilcoxon rank test at the $5 \%$ significance level to test if the intake was significantly higher than the EAR for nutrients that reported a NAR greater than 1.

energy intake often occurs when using $24 \mathrm{~h}^{\text {recalls }}{ }^{(51)}$. The results report the central tendency by use of the median, the minimum and maximum.

To report the diversity of the diet, Dietary Species Richness (DSR; the total number of species) and TFDS (the number of locally produced and wild species) were reported using the methodology of Lachat et al. ${ }^{(9)}$ and Roche et $a l .{ }^{(34)}$, respectively. In addition to dietary diversity, to analyse the quality of the diet, the Minimum Dietary Diversity for Women of reproductive age (MDD-W) was calculated. Foods were grouped into ten food groups as proposed in the literature ${ }^{(52)}$. MDD-W is a dichotomous dietary quality indicator that shows micronutrient adequacy of the diet when more than five food groups (out of the ten) are consumed and has been validated for developing countries ${ }^{(53)}$. The food groups included: (i) all starchy and staple foods; (ii) beans and peas; (iii) nuts and seeds; (iv) dairy; (v) flesh foods; (vi) eggs; (vii) vitamin A-rich vegetables and fruits; (viii) other fruits; (ix) vitamin A-rich dark green vegetables; and (x) other vegetables (analysis with MSM software version 1.0.1 excluded the last two because these were not consumed by any respondent).

The nutrient intake data were imputed for missing data and then analysed using R. For those women who were not at home at the second visit ( $n$ 11), missing data imputation was conducted using multivariate imputation by chained equations (MICE) by the second researcher (H.C.-V.) using the $\mathrm{R}$ package mice ${ }^{(54)}$. The latter used ten imputations per missing datum, and the mean was used to replace the missing value. MICE draws from the theoretical joint posterior distribution of the missing data by specifying for each incomplete variable a conditional model for the missing data given a set of other variables (fully conditional specification). Starting from an initial imputation, MICE draws imputations by integrating over the conditional densities. By modelling only conditional distributions, many complexities of real multivariate data such as predictors of a different type, the existence of non-linear relationships or interactions between variables and circular dependence can be addressed ${ }^{(54,55)}$. For the present study, MICE imputed each incomplete nutrient by generating plausible synthetic values given the other nutrients in the data. In R, we used the default values of the $\mathrm{R}$ mice $(\cdot)$ function with predictive mean matching for the conditional models. MICE has been used in medical research ${ }^{(56)}$. Various authors have shown the satisfactory performance of this $\operatorname{method}^{(57-59)}$.

Because we did not find statistical evidence of normality for the nutrient data as revealed by Quantile-Quantile plots and Kolmogorov-Smirnov tests (results not shown), we reported the first quartile, median and third quartile for nutrient intakes (see Table 2). Reporting these quartiles and the median aims to summarize the diet composition data and eases the interpretation for non-scientist readers ${ }^{(60)}$. Note that these measures cannot be summed up to obtain the composition per $100 \mathrm{~g}$, nor for nutrients representing sources of energy (proteins, carbohydrates, fibres, fats), when applying the Atwater equation to estimate kilojoules.

The Nutrient Adequacy Ratio (NAR) was used as a measure of nutrient adequacy. NAR is obtained by dividing the quantified intake of a nutrient by the Estimated Average Requirement (EAR), as proposed in the literature ${ }^{(30,61)}$. The EAR is the intake sufficient to meet $50 \%$ of the nutrient requirements (which in a normal distribution is the mean or median). Therefore, a person who consumes as much as the EAR for a specific nutrient has $50 \%$ probability to meet the nutrient requirement. In this line, the EAR was used as the cut-off point. Table 2 shows the percentage of the population below the EAR (except for Fe because its distribution is known to be skewed) ${ }^{(62)}$. Values below the EAR show that interventions are needed as the probability of adequacy is less than $50 \%{ }^{(62)}$. Calculating NAR allows us to easily assess if the requirements are met. Values closer to 1 indicate that the intake is closer to the requirements. The EAR for protein was $0.66 \mathrm{~g} / \mathrm{kg}$ assuming body weight 
of $55 \mathrm{~kg}$ and quality and digestibility of the protein as for eggs ${ }^{(63,64)}$. The requirement for fat intake was converted from $20 \%$ of total energy consumption to grams of fat using the Atwater factor of $37.656 \mathrm{~kJ} / \mathrm{g}^{(65)}$. The requirement for carbohydrate intake ( $50 \%$ of the total energy intake) and fibre was for non-pregnant and not breast-feeding female adults ${ }^{(66,67)}$. The Ca requirement covered dermal and urinary losses ${ }^{(68,69)}$. The Fe requirement covered menstruation losses and assumes body weight of $55 \mathrm{~kg}$ and $12 \%$ bioavailability as the diet is composed of rice, fruits and animal protein ${ }^{(68,70)}$. For the calculation of $\mathrm{Zn}$ requirement, we used a body weight of $55 \mathrm{~kg}$ and a bioavailability of $30 \%$ since local diets consist of both animal and plant foods ${ }^{(68)}$. The EAR for vitamin A was $8.4 \mu \mathrm{g} / \mathrm{kg}$ and assumed a body weight of $55 \mathrm{~kg}^{(71)}$. The EAR for vitamin $\mathrm{C}$ assumed an absorption of $80 \%$ and a body weight of $55 \mathrm{~kg}^{(72)}$. In order to obtain robust results to non-normal data, we used the non-parametric Wilcoxon signed-rank test to test if the intake was significantly higher than the EAR for nutrients that reported a NAR greater than $1^{(30,61)}$.

In the same line, linear quantile mixed models ${ }^{(73)}$ were fitted to find whether there is a significant association between DSR and Mean Adequacy Ratio (MAR; see Table 3). The latter is a measure of the adequacy of the diet, which is the average of all NAR (truncated to 1). Similarly, we used linear quantile mixed models to investigate the association between consumption of local species and MAR. To adjust for potential confounding, for both analyses we considered age, occupation and education as fixed effects and village as random effect. The Akaike information criterion was used to select the best model in each analysis. We used the function $\operatorname{lqmm}(\cdot)$ in the $\mathrm{R}$ package $\mathrm{lqmm}^{(74)}$ to fit linear quantile mixed models. The argument 'tau' was set to 0.5 to fit models for the conditional median of MAR, while we used the default settings for the rest of the arguments of the $\operatorname{lqmm}(\cdot)$ function. This implies the assumption of a diagonal variance-covariance matrix for the random effects.

The median and interquartile range values of the ten most-consumed TF for the eight MDD-W food groups were calculated using the MSM (see Table 4). As mentioned above, locally cultivated vitamin A-rich dark green and other vegetables were not recalled during the interviews and therefore these were not reported in the results. The amount of each food consumed during the two-day record (first and second visit) and its consumption frequency (third visit) were imported into the MSM software version 1.0.1. This method applies two regression models, one for the positive daily intake data and one for the event of consumption, to simulate the usual diet. MSM estimates the individual probability of consuming a specific food or nutrient by means of a logistic regression model that used age and interviewer codes as covariates. Withinperson variability was reduced by using the quantified intakes from the first visit and second visit, and using the frequency of consumption from the FFQ (third visit).
The MSM uses the residuals of the regression to estimate variances and a Box-Cox transformation to estimate interand intra-individual variance.

The median intake of total fruits and of total vegetables was compared with the food intake recommendations for the prevention of chronic diseases ${ }^{(75)}$. Food-based dietary guidelines are often used to guide food and nutrition policies, health promotion interventions and disease prevention $^{(68)}$. The non-parametric Wilcoxon signed-rank test was conducted to test for a significant difference between the median total fruit intake and the median total vegetable intake, and the recommended intake of $200 \mathrm{~g}$ fruits and $200 \mathrm{~g}$ vegetables, respectively, correcting for village. Because the recommendations of Kromhout ${ }^{(75)}$ (2016) are more recent than those of $\mathrm{WHO}^{(76)}$ (2003), we used the $200 \mathrm{~g}$ recommendation separately for fruits and vegetables rather than the $400 \mathrm{~g}$ merged. Also, the Wilcoxon signed-rank test was used to compare the median intake of ruminant meat with the recommendation of $50 \mathrm{~g} / \mathrm{d}$ for sustainable diets, which is the maximum recommended to mitigate greenhouse gas emissions ${ }^{(77)}$.

\section{Results}

Table 1 shows the demographic characteristics of the rural respondents. The age of the studied women ranged between 18 and 69 years, with a median age of 39 years. Visited households had a maximum of 13 inhabitants and a median of 5 . Most of the women practised family agriculture, whereas the minority were students. Regarding education, most of the studied women received only primary education.

The diet during the rainy season of 2011 was based on 140 different food items. The studied women consumed at least ten different foods per day. The median DSR was 16 (IQR 4), a minimum of 8 and maximum of 24 , from a total of 119 species. During the period of data collection, seventy TF (meaning only locally cultivated and wild food species) were consumed. These included fifty plants species, thirteen animal species and seven medicinal plants (the list of species is available elsewhere $\left.{ }^{(78)}\right)$. The consumption of these TF led to a median TFDS of 6 (IQR 3), a minimum of 2 and a maximum of 14 .

The median intake of protein, fat, total carbohydrates, Fe and vitamin $\mathrm{C}$ was each significantly higher than the EAR at the $5 \%$ significance level, meaning that more of the required nutrients are consumed (NAR $>1$ ). The MAR calculated for nine nutrients (truncated to 1 ) was $0 \cdot 78$, meaning that the diet is adequate for most of its nutrients (see Table 2).

The diversity of locally cultivated and wild foods provided $38.6 \%$ of total energy intake. The latter excludes seven medicinal plants that do not contribute to energy because they are used as infusions.

The results of the linear quantile mixed models are shown in Table 3. Only the best models according to the 
Table 3 Estimates of the effect of total number of edible species consumed (Dietary Species Richness; DSR) and number of locally cultivated and wild species consumed (Traditional Food Diversity Score; TFDS) on the Mean Adequacy Ratio (MAR) of women's diet in Guasaganda, Ecuador, during the rainy season of $2011(n$ 178)

\begin{tabular}{lcc}
\hline Model & Estimate & $P$ value \\
\hline MAR (nine nutrients) - DSR = Village† & 0.019 & $<0.001$ \\
MAR (nine nutrients) - & 0.027 & $<0.001$ \\
TFDS + Village† + Education & 0.052 & $<0.001$ \\
$\begin{array}{l}\text { MAR (six micronutrients) - } \\
\text { TFDS + Village† + Education }\end{array}$ & 0.033 & $<0.001$ \\
$\begin{array}{l}\text { MAR (three macronutrients) - } \\
\text { TFDS + Village† + Occupation }\end{array}$ & & \\
\hline
\end{tabular}

*The effect of DSR on MAR (nine nutrients) in the first model was tested at the $5 \%$ significance level. The effect of local species (TFDS) on quality of the diet (MAR for all nine nutrients, for six micronutrients and for three macronutrients) was tested at the $1.66 \%$ significance level by the Bonferroni correction.

†Best models shown above include a random intercept for village.

Akaike information criterion are shown. For instance, the best model to investigate the association between the total number of species (DSR) and the quality of the diet (MAR for all nine nutrients) included our factor of interest, DSR, and a random intercept for village. We found a significant association between total number of total species (DSR) and quality of the diet (MAR for all nine nutrients, $P<0.001)$. Likewise, we found a significant association between local species (TFDS) and quality of the diet (MAR for all nine nutrients, for six micronutrients and for three macronutrients) at the $1.66 \%$ significance level with the Bonferroni correction.

The studied women had a median MDD-W of 6 (with a minimum of 2 and a maximum of 8 ), out of 10 food groups, which is higher than the cut-off of 5 , meaning that the studied diet is adequate in micronutrients ${ }^{(53)}$. Table 4 presents the usual intake of the top ten TF within MDD-W food groups.

\section{Additional findings}

The median fruit $(91.73 \mathrm{~g})$ and vegetable $(25.56 \mathrm{~g})$ intake was significantly lower than the $200 \mathrm{~g}$ for each food group, respectively, recommended for preventing chronic diseases $^{(75)}$ (both $P<0.001$ ). Analysis of ruminant meat intake showed that the median intake $(63.86 \mathrm{~g})$ was significantly higher than the maximum $50 \mathrm{~g}(P<0.001)$ recommended for sustainable diets ${ }^{(77)}$.

An ingredient considered a condiment and used daily in almost every dish was coriander (Coriandrum sativum L.), which provided $4 \%$ of the total vitamin A intake but was not counted as a vegetable within the MDD-W score.

\section{Discussion}

Results in the present study show a significant association between TF and MAR, after adjustment for education, village and occupation, during the rainy season of 2011. Results show that the studied diet is adequate for most of the studied nutrients, mainly micronutrients (MAR $=0 \cdot 78$ ). Dietary diversity is based on 140 different food items, from which half are locally cultivated and wild species. About six food species (TFDS) are consumed daily from local and wild sources. MDD-W of 6 shows the adequacy of micronutrient intake ${ }^{(53)}$. The most consumed TF, cultivated and wild, have been identified and quantified, which serves for future interventions that aim to promote TF consumption in the area.

Our study supports findings of similar studies done in rural communities in South $\operatorname{America}^{(34)}$, Canada ${ }^{(12)}$, Africa $^{(5)}$ Oceania $^{(79)}$ and South-East Asia ${ }^{(19)}$ in that there is statistical evidence to state that TF (whether cultivated or wild) contribute to a share of micronutrient intake. We may, however, have reported higher values than the referred studies because we merged cultivated and wild foods.

Our study differs from Lachat et al. ${ }^{(9)}$ in that we counted only species which are locally produced (TFDS) and excluded foods that are not in the local environment. Our findings suggest that a local dietary species richness indicator can be useful for rural studies. According to Berti, the counting of food species has a high influence on the results and conclusions of the study ${ }^{(80)}$.

Our results show that an increase in fruit consumption is required to reach the food intake recommendation $(200 \mathrm{~g} / \mathrm{d})$ and prevent thereby chronic diseases ${ }^{(75)}$. We also suggest that the studied rural women need to consume a higher amount and diversity of vegetables. Consumption of locally cultivated and wild plant species that contribute to vitamin A intake is marginal. It is recommended to increase the cultivation of leafy vegetables or collect wild leafy vegetables to reach the $200 \mathrm{~g}$ recommendation ${ }^{(75)}$. Eating leafy vegetables has been reported to contribute to vitamin A, C and Ca intakes when $50 \mathrm{~g} / \mathrm{d}$ are consumed ${ }^{(19)}$. The latter highlights the importance of consuming green leafy vegetables for micronutrient intake.

Ruminant meat consumption was reported as an additional finding regarding the sustainability of the diet. Results show that beef is the first local food source of energy. The population consumes significantly more than $50 \mathrm{~g}$ of ruminant meat daily which is the maximum recommended to mitigate greenhouse gas emissions ${ }^{(77)}$. Reducing the consumption of red meat to meet energy needs has shown to decrease diet-associated greenhouse gas emissions by up to $10 \cdot 7 \%{ }^{(81,82)}$. Reducing the consumption of meat is, however, controversial because it supplies important nutrients such as $\mathrm{Fe}, \mathrm{Ca}$ and vitamin $\mathrm{B}_{12}{ }^{(30)}$.

A novel approach of the present study is the use of MICE for the imputation of missing values. We suggest that the use of this method is adequate for rural studies based on previous literature ${ }^{(57-59)}$. Often, rural studies face the limitation that participants drop out of the study, originating missing data during sampling. In this case, the second visit 


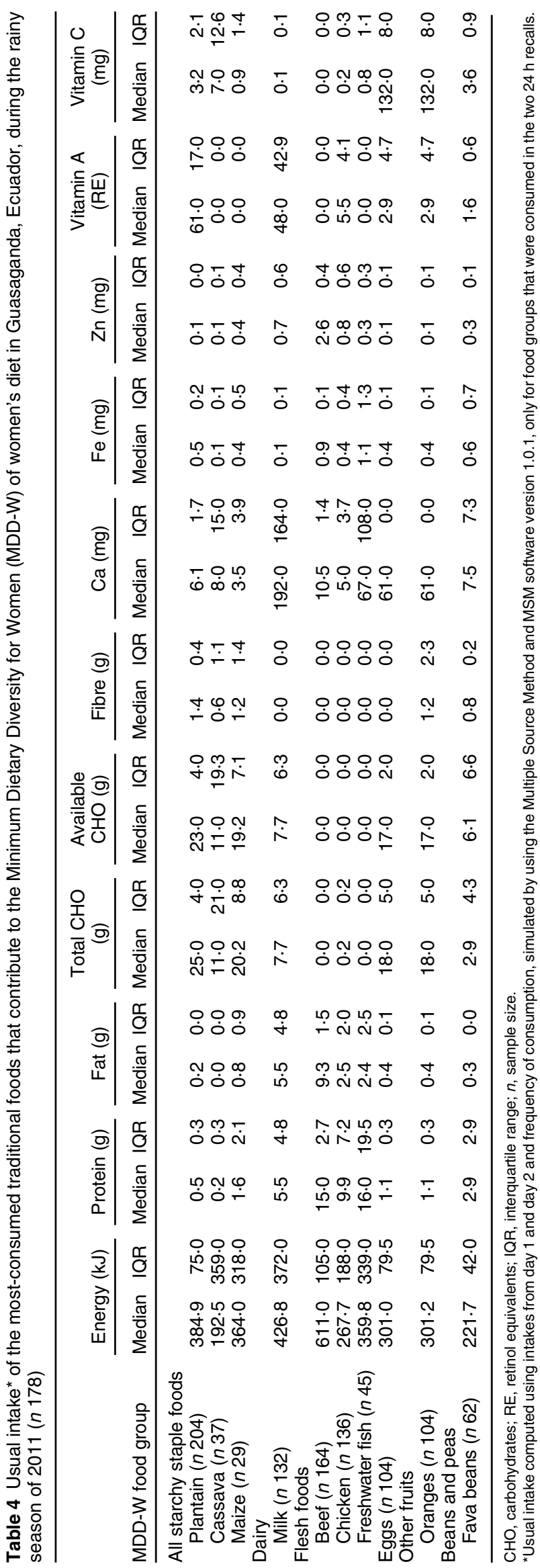

was not completed because a torrential rainfall limited the access to some households ${ }^{(83)}$. We recommend adding $15 \%$ of households for contingency to have enough sample data.

Future studies on TF in Ecuador need to have access to more accurate and updated FCT $^{(84)}$. High-quality FCT should be representative of national foods including the habitual portions ${ }^{(85)}$. Nutrient content analysis of TF needs to be conducted by certified laboratories (e.g. ISO 17025) to report accurate and reliable FCT. This will allow nutritionists to identify micronutrient-rich foods that need to be promoted during healthy eating interventions. Prior to nutrient analysis, each species should be adequately identified, together with its cooking method and its geographical area such as the FCT of Guatemala ${ }^{(85)}$. For example, using a standardized sampling and analytical protocol on 171 genotypes of Musa spp. fruits from different geographical areas allowed identification of provitamin A-rich fruits ${ }^{(86)}$.

\section{Conclusion}

Cultivated and wild foods from rural areas provide a small share of energy intake, yet they highly contribute micronutrients which are essential for nutrient security. The evidence shows a positive association between TF consumption and micronutrient adequacy. The traditional diet of rural Guasaganda is based on a combination of plant and animal products which need to be balanced towards sustainable diets. However, current fruit and vegetable consumption does not meet the recommendation (each $200 \mathrm{~g} / \mathrm{d}$ ) for the prevention of chronic diseases. Thus, it is suggested to increase the cultivation and consumption of fruits, and particularly vegetables, in home gardens. Furthermore, recommendations include replacing a share of red meat with plant foods to have a traditional diet which is environmentally friendly and helps progress towards Sustainable Development Goal 2.

\section{Acknowledgements}

Acknowledgement: The authors are grateful for the advice received from Carl Lachat (Ghent University). Financial support: This work was funded by the International Foundation for Science (grant number E4954-1). The funding covered all fieldwork conducted to collect data, excluding the honoraria of the authors. The International Foundation for Science had no role in the design, analyses or writing of this article. Conflict of interest: No conflicts of interest are perceived. Authorship: The study was designed by D.P., R.E. and P.V.D. Data were collected by D.P. Data analysis was conducted by D.P. (bioscientist) and H.C.-V. (statistician); and R.E. and P.V.D. contributed to the 
interpretation of results. D.P., H.C.-V., R.E. and P.V.D. wrote the manuscript. Ethics of human subject participation: This study was conducted according to the guidelines laid down in the Declaration of Helsinki and all procedures involving human subjects were approved by the ethical committee of Ghent University (B670201213216) and the Ecuadorian Ministry of Public Health (MSP-DIS00562012). Written informed consent was obtained from all subjects.

\section{References}

1. Galli F (2018) Traditional food: definitions and nuances. In Case Studies in the Traditional Food Sector, pp. 3-24 [A Cavicci and C Santini, editors]. Duxford: Woodhead Publishing/Elsevier.

2. Kuhnlein H \& Receveur O (1996) Dietary change and traditional food systems of indigenous peoples. Annu Rev Nutr 16, 417-442.

3. Hinrichs CC (2003) The practice and politics of food system localization. J Rural Stud 19, 33-45.

4. Vinceti B, Termote C, Ickowitz A et al. (2013) The contribution of forests and trees to sustainable diets. Sustainability 5, 4797.

5. Termote C, Bwama Meyi M, Dhed'a B et al. (2012) A biodiverse rich environment does not contribute to a better diet: a case study from DR Congo. PLoS One 7, 30533.

6. Penafiel D, Lachat C, Espinel R et al. (2011) A systematic review on the contributions of edible plant and animal biodiversity to human diets. EcoHealth 8, 381-399.

7. Powell B, Thilsted SH, Ickowitz A et al. (2015) Improving diets with wild and cultivated biodiversity from across the landscape. Food Secur 7, 535-554.

8. Kennedy G, Stoian D, Hunter D et al. (2017) Mainstreaming Agrobiodiversity in Sustainable Food Systems. Food Biodiversity for Healthy, Diverse Diets. Rome: Bioversity International.

9. Lachat C, Raneri JE, Smith KW et al. (2018) Dietary species richness as a measure of food biodiversity and nutritional quality of diets. Proc Natl Acad Sci U S A 115, 127-232.

10. Roos N, Islam MM \& Thilsted SH (2003) Small indigenous fish species in Bangladesh: contribution to vitamin A, calcium and iron intakes. J Nutr 133, 4021-4026.

11. Ogle BM, Johansson M, Tuyet $\mathrm{H}$ et al. (2001) Evaluation of the significance of dietary folate from wild vegetables in Vietnam. Asia Pac J Clin Nutr 10, 216-221.

12. Kuhnlein HV, Barthet V, Farren A et al. (2006) Vitamins A, D, and $\mathrm{E}$ in Canadian Arctic traditional food and adult diets. J Food Compost Anal 19, 495-506.

13. F M'Kaibi, Steyn NP, Ochola S et al. (2015) Effects of agricultural biodiversity and seasonal rain on dietary adequacy and household food security in rural areas of Kenya. BMC Public Health 15, 422.

14. Lykke AM, Mertz OLE \& Ganaba S (2002) Food consumption in rural Burkina Faso. Ecol Food Nutr 41, 119-153.

15. Frei M \& Becker K (2004) Agro-biodiversity in subsistenceoriented farming systems in a Philippine upland region: nutritional considerations. Biodivers Conserv 13, 1591-1610.

16. Rais M, Pazderka B \& vanLoon GW (2009) Agriculture in Uttarakhand, India - biodiversity, nutrition, and livelihoods. J Sustain Agric 33, 319-335.

17. Powell C, Hall J \& Johns T (2011) Forest cover, use and dietary intake in the East Usambara mountains, Tanzania. Int For Rev 13, 305-317.

18. Begossi A \& Richerson PJ (1993) Biodiversity, family income and ecological niche - a study on the consumption of animal foods on Buzios Island (Brazil). Ecol Food Nutr 30, 51-61.

19. Ogle BM, Hung P \& Tuyet H (2001) Significance of wild vegetables in micronutrient intakes of women in Vietnam: an analysis of food variety. Asia Pac J Clin Nutr 10, 21-30.

20. Osemeobo GJ (2001) Wild plants in everyday use: conservation towards sustainable livelihoods in Nigeria. Int J Sustain Dev World Ecol 8, 369-379.

21. Passos CJS, Mergler D, Fillion M et al. (2007) Epidemiologic confirmation that fruit consumption influences mercury exposure in riparian communities in the Brazilian Amazon. Environ Res 105, 183-193.

22. N Roos, Thorseng H, Chamnan C et al. (2007) Iron content in common Cambodian fish species: perspectives for dietary intake in poor, rural households. Food Chem 104, 1226-1235.

23. Roos N, Chamnan C, Loeung D et al. (2007) Freshwater fish as a dietary source of vitamin A in Cambodia. Food Chem 103, 1104-1111.

24. Bogard JR, Thilsted SH, Marks GC et al. (2015) Nutrient composition of important fish species in Bangladesh and potential contribution to recommended nutrient intakes. J Food Compost Anal 42, 120-133.

25. Aguilar H \& Cartagena I (2010) Diversidad y Abundancia de Plantas Útiles en 3 Estratos de Altitud de la Zona de La Maná (Diversity and Abundance of Plants in 3 Altitude Levels in La Mana). Guayaquil: Escuela Superior Politecnica del Litoral, Facultad de Mecanica y Ciencias de la Produccion; available at http://www.dspace.espol.edu.ec/handle/123456789/ 13425 (accessed February 2011).

26. Instituto Nacional de Estadisticas y Censos (2010) Estadisticas de Población y Migración (Statistical Data of Population and Migration), Cotopaxi, La Mana. Quito: INEC.

27. Freire W, Ramírez M, Belmont P et al. (2014) Encuesta Nacional de Salud y Nutricion: ENSANUT-ECU 2012 (National Health and Nutrition Survey: ENSANUT-ECU 2012). Quito: Ministerio de Salud Publica del Ecuador e Instituto Nacional de Estadisticas y Cesos.

28. Salvador Castell G, Serra-Majem L \& Ribas-Barba L (2015) What and how much do we eat? 24-hour dietary recall method. Nutr Hosp 31, Suppl. 3, 46-48.

29. Fiedler JL, Martin-Prevel Y \& Moursi M (2013) Relative costs of 24-hour recall and Household Consumption and Expenditures Surveys for nutrition analysis. Food Nutr Bull 34, 318-330.

30. Otten J, Hellwig J \& Meyers L (2006) Dietary Reference Intakes: The Essential Guide to Nutrient Requirements. Washington, DC: National Academies Press.

31. Willett WC (1998) Nutritional Epidemiology. New York: Oxford University Press.

32. Gibson RS (2005) Principles of Nutritional Assessment. Oxford: Oxford University Press.

33. Food and Agriculture Organization of the United Nations (2010) FAOSTAT: Production of the 20 most important food and agricultural commodities (ranked by value). http:// faostat.fao.org/site/339/default.aspx (accessed February 2012).

34. Roche M, Creed-Kanashiro H, Tuesta I et al. (2008) Traditional food diversity predicts dietary quality for the Awajún in the Peruvian Amazon. Public Health Nutr 11, 457-465.

35. Magnani R (1997) Sampling Guide. Washington, DC: Food and Nutrition Technical Assistance Project, Academy for Educational Development.

36. Swindale A \& Ohri-Vachaspati P (2005) Measuring Household Food Consumption: A Technical Guide. Washington, DC: Food and Nutrition Technical Assistance Project. Academy for Educational Development. 
37. Bonham CD (1989) Measurements of Terrestrial Vegetation. New York: John Wiley \& Sons.

38. Elzinga CL, Salzer DW \& Willoughby JW (1998) Measuring \& Monitoring Plant Populations. BLM Technical Reference no. 1730-1. Denver, CO: Bureau of Land Management.

39. Freile JF \& Bonaccorso E (2011) Aves de Ecuador, Versión 1.0. http://zoologia.puce.edu.ec/Vertebrados/aves/AvesEcuador/ default.aspx (accessed January 2013).

40. Ramiro B (2011) Lista de peces de agua dulce e intermareales del Ecuador (List of fresh water of Ecuador). http://bibdigital. intermareales\%20Ecuador\%202012Politecnica30\%283\%29. pdf (accessed August 2019).

41. Burneo S \& Boada C (2012) MammaliaWebEcuador, Versión 2012.1. http://zoologia.puce.edu.ec/Vertebrados/ Mamiferos/MamiferosEcuador/default.aspx (accessed September 2015).

42. US Department of Agriculture (2007) USDA Table of Nutrient Retention Factors, Release 6. https://data.nal.usda.gov/ dataset/usda-table-nutrient-retention-factors-release-6-2007 (accessed August 2019).

43. Berstronm L (1996) Nutrient losses and gains in the preparation of foods: NLG project. Food Chem 57, 77-78.

44. Charrondiere UR \& Burlingame B (2011) Report on the FAO/ INFOODS Compilation Tool: a simple system to manage food composition data. Food Compost Anal 24, 711-715.

45. Instituto Nacional de Salud, Centro Nacional de Alimentación y Nutrición (2009) Tablas Peruanas de Composición de Alimentos. Lima: INS.

46. Instituto de Nutricion de Centroamerica y Panama, Organizacion Panamericana de la Salud (2007) Tabla de Composición de Alimentos de Centro America. Guatemala: INCAP.

47. Ministerio de Provision Social y Sanidad, Instituto Nacional de Nutrición (1965) Tabla de Composición de Alimentos Ecuatorianos. Quito: INN.

48. US Department of Agriculture (2014) National Nutrient Database for Standard Reference Release 28, V.2.3.8. https://ndb.nal.usda.gov/ndb/foods (accessed August 2019).

49. European Food Safety Authority, Panel on Dietetic Products, Nutrition, and Allergies (2016) Draft Scientific Opinion. Scientific Opinion on Dietary Reference Values for vitamin D. https://www.efsa.europa.eu/sites/default/ files/consultation/160321.pdf (accessed August 2019).

50. Ministerio de Salud Pública (2013) Ecuador cumple exitosamente con el manejo de la deficiencia de yodo (Ecuador has successfully eradicated iodine deficiency). http://www.ladeficiencia-de-yodo/ (accessed February 2015).

51. Johansson G, Wikman A, Ahren AM et al. (2001) Underreporting of energy intake in repeated 24-hour recalls related to gender, age, weight status, day of interview, educational level, reported food intake, smoking habits and area of living. Public Health Nutr 4, 919-927.

52. Food and Agriculture Organization of the United Nations (2014) Introducing the Minimum Dietary Diversity Women (MDD-W). Global Dietary Diversity Indicator for Women. http://www.fao.org/fileadmin/templates/nutrition assessment/Dietary_Diversity/Minimum_dietary_diversity__women_MDD-W__Sept_2014.pdf (accessed September 2014).

53. Food and Agriculture Organization of the United Nations \& USAID's Food and Nutrition Technical Assistance III Project (FANTA), managed by FHI 360 (2016) Minimum Dietary Diversity for Women: A Guide for Measurement. Rome: FAO.

54. Van Buuren S \& Groothuis-Oudshoorn K (2011) Multivariate imputation by chained equations in R. J Stat Softw $\mathbf{4 5}$, $1-67$.

55. Van Buuren S (2012) Flexible Imputation of Missing Data. Boca Raton, FL: CRC, Chapman and Hall.
56. Van Buuren S (2007) Multiple imputation of discrete and continuous data by fully conditional specification. Stat Methods Med Res 16, 219-242.

57. Van Buuren S, Brand JPL, Groothuis-Oudshoorn CG et al. (2006) Fully conditional specification in multivariate imputation. J Stat Comput Simul 76, 1049-1064.

58. Cevallos Valdiviezo H \& Van Aelst S (2015) Tree-based prediction on incomplete data using imputation or surrogate decisions. Inf Sci 311, 163-181.

59. Hapfelmeier A, Hothorn T \& Ulm K (2012) Recursive partitioning on incomplete data using surrogate decisions and multiple imputation. Comput Stat Data Anal 56, 1552-1565.

60. Lang TA \& Secic M (editors) (2006) How to Report Statistics in Medicine: Annotated Guidelines for Authors, Editors, and Reviewers. Philadelphia, PA: American College of Physicians.

61. Murphy SP (2008) Using DRIs for dietary assessment. Asia Pac J Clin Nut 17, 299-301.

62. Murphy S, Munro I \& Young V (2000) Dietary Reference Intakes: Applications in Dietary Assessment. Washington, DC: National Academies Press.

63. Food and Agriculture Organization of the United Nations/ World Health Organization (1973) Summary of requirements for energy and protein: adult women. Ad Hoc Expert Committee. http://www.fao.org/docrep/003/aa040e/aa040 e09.htm (accessed January 2014).

64. European Food Safety Authority, Panel on Dietetic Products, Nutrition, and Allergies (2012) Scientific Opinion on Dietary Reference Values for protein. https://www.efsa.europa.eu/ en/efsajournal/pub/2557 (accessed August 2019).

65. Food and Agriculture Organization of the United Nations/ World Health Organization (1994) Experts' recommendations on fats and oils in human nutrition: adult woman. http://www.fao.org/docrep/t4660t/t4660t02.htm (accessed January 2014)

66. Institute of Medicine (2010) Dietary Reference Intakes Tables and Application. Macronutrients Summary. http://iom. nationalacademies.org/Activities/Nutrition/SummaryDRIs/ DRI-Tables.aspx (accessed February 2015).

67. European Food Safety Authority, Panel on Dietetic Products, Nutrition, and Allergies (2010) Scientific Opinion on Dietary Reference Values for carbohydrates and fibre. https://www. efsa.europa.eu/en/efsajournal/pub/1462 (accessed August 2019).

68. Food and Agriculture Organization of the United Nations/ World Health Organization (2004) Expert consultation on human vitamin and mineral requirements. Adult woman. http://whqlibdoc.who.int/publications/2004/9241546123.pdf (accessed April 2010).

69. European Food Safety Authority, Panel on Dietetic Products, Nutrition, and Allergies (2015) Scientific Opinion on Dietary Reference Values for calcium. https://www.efsa.europa.eu/ en/efsajournal/pub/4101 (accessed August 2019).

70. European Food Safety Authority, Panel on Dietetic Products, Nutrition, and Allergies (2015) Scientific Opinion on Dietary Reference Values for iron. https://www.efsa.europa.eu/en/ efsajournal/pub/4254 (accessed August 2019).

71. European Food Safety Authority, Panel on Dietetic Products, Nutrition, and Allergies (2015) Scientific Opinion on Dietary Reference Values for vitamin A. https://www. efsa.europa.eu/en/efsajournal/pub/4028 (accessed August 2019).

72. European Food Safety Authority, Panel on Dietetic Products, Nutrition, and Allergies (2013) Scientific Opinion on Dietary Reference Values for vitamin C. https://www.efsa.europa. eu/en/efsajournal/pub/3418 (accessed August 2019).

73. Geraci M \& Bottai M (2014) Linear quantile mixed models. Stat Comput 24, 461-479.

74. Geraci M (2014) lqmm: linear quantile mixed models. R package version 1.5. http://CRAN.R-project.org/package=lqmm (accessed August 2019). 
75. Kromhout D, Spaaij CJK, de Goede J et al. (2016) The 2015 Dutch food-based dietary guidelines. Eur J Clin Nutr $\mathbf{7 0}$, 869-878.

76. World Health Organization (2003) Diet, Nutrition and the Prevention of Chronic Diseases. Report of a Joint FAO/ WHO Expert Consultation. WHO Technical Report Series no. 916. Geneva: WHO.

77. McMichaelAJ, PowlesJW, ButlerCD et al. (2007) Food, livestock production, energy, climate change, and health. Lancet 370, 1253-1263.

78. Penafiel D, VanhoveW, Van Damme P et al. (2019) Food biodiversity includes both locally cultivated and wild food species in Guasaganda, Central Ecuador. J Ethnic Foods (In the Press).

79. Englberger L, Aalbersberg W, Schierle J et al. (2006) Carotenoid content of different edible pandanus fruit cultivars of the Republic of the Marshall Islands. I Food Compost Anal 19, 484-494.

80. Berti P (2015) Relationship between production diversity and dietary diversity depends on how number of foods in counted. Proc Natl Acad Sci USA 112, E5656.

81. Vieux F, Darmon N, Touazi D et al. (2012) Greenhouse gas emissions of self-selected individual diets in France: changing the diet structure or consuming less?Ecol Econ 75, 91-101.
82. Auestad N \& Fulgoni VL (2015) What current literature tells us about sustainable diets: emerging research linking dietary patterns, environmental sustainability, and economics. $A d v$ Nutr 6, 19-36.

83. Mejia A (2016) Vía Guayacán - Guasaganda - Pucayacu, fue declarada en emergencia (Road from Guayacan, Guasaganda until Pucayacu declared in emergency). http:// www.lagaceta.39690:via-guayacan-guasaganda-pucayacufue-declarada-en-emergencia\&catid=68\&Itemid=104\&lang= es (accessed June 2016).

84. Ramirez MJ, Silva-Jaramillo MK, Belmont P et al. (2017) Tabla de Composición de Alimentos para Ecuador: Compilación del Equipo Técnico de la ENSANUT-ECU, 2012. Quito: Ministerio de Salud Pública del Ecuador.

85. Food and Agriculture Organization of the United Nations, International Network of Food Data Systems (INFOODS) (2007) Food composition challenges. http://www.fao.org/ infoods/infoods/food-composition-challenges/en/ (accessed October 2012).

86. Davey MW, Van den Bergh I, Markham R et al. (2009) Genetic variability in Musa fruit provitamin A carotenoids, lutein and mineral micronutrient contents. Food Chem 115, 806-813. 